\title{
Antropología y Ecología: historia de un romance.
}

\author{
Victor M. Toledo
}

\section{Introducción}

$\mathrm{L}$ a civilización industrial está en crisis y con ella sus va lores y expectativas y su visión del mundo. E1 cuestionamiento incluye la forma o modo particular de aprehender la realidad, es decir, alcanza a cuestionar al conocimiento científico o moderno. Por ello, un número creciente de pensadores han inciado desde hace más de una década una serie de reflexiones y críticas tendientes a hacer evidentes los limites del conocimiento científico en su versión dominante, hegemónica o convencional. "La ciencia, afirma Leff (2000: 31), que se pensaba liberadora del atraso y de la opresión, del primitivismo y del subdesarrollo, ha generado un desconocimiento del mundo, un conocimiento que no sabe de sí mismo; que gobierna un mundo alienado del que desconocemos su conocimiento especializado y las reglas del poder que lo gobiernan. El conocimiento ya no representa la realidad".

Esta «revolución conceptual» como le ha denominado Naredo (1992), está siendo alimentada de una nueva visión geocéntrica y por una nueva conciencia global de la crisis de la modernidad e intenta superar «el 'neo-oscurantismo' sin precedentes al que conduce la especialización científica en campos inconexos...» (:139). El conjunto de cuestionadores incluye corrientes epistemológicas tan diversas como las de "el pensamiento complejo" (Morin,1990), "la teoría de los sistemas complejos" (García, 1994), "la complejidad ambiental" (Leff, 2000) la "teoría de la resiliencia socio-ecológica" (Berkes \& Folke, 1998; Gunderson \& Holling, 2001), o la llamada "ciencia post-normal" (Funtowicz \& Ravetz, 1993; 1998). Todas estas (contra-) corrientes han surgido como reacciones frente a las limitadas capacidades de la ciencia actual y la necesidad de reformularla, para lo cual proponen nuevos enfoques que entre otras cosas buscan la integración de las ciencias de la naturaleza con las ciencias sociales y humanas.
$Y$ es que como fue señalado por Lewis Mumford en su libro The Transformation of Man (1972): «...hasta ahora hemos vivido esencialmente en mundos parciales...Ni la vaga totalidad subjetiva adquirida por el hombre primitivo, ni al otro extremo, la objetividad fragmentaria y precisa investigada por la ciencia, pueden rendir justicia a todas las dimensiones de la experiencia humana». Se trata entonces de reconocer el surgimiento de un renovado aparato conceptual de la ciencia que aparece como respuesta a los limitados análisis simplifcadores y reduccionistas del enfoque analítico-parcelario. Un enfoque que dentro de las ciencias sociales ha privilegiado una tendencia a crear abstracciones desespacializadas y desnaturalizadas $y$, dentro de las ciencias naturales, tratamientos sectoriales en total desconexión con los fenómenos sociales y humanos.

Teniendo como contexto lo anteriormente señalado, el presente ensayo hace una somera revisión de las relaciones que se han establecido entre dos campos del conocimiento que habitualmente existen de manera separada: la antropología y la ecología. La revisión se antoja interesante en tanto que aborda un fenómeno epistemológico que no es un caso particular o aislado, sino que corre en paralelo a otros muchos intentos por hacer confluir las ciencias sociales y humanas con las ciencias de la natutraleza (véase el siguiente apartado), confirmando de paso que vivimos una época de crisis y cambios en el conocimiento, una suerte de "ebullición epistémica".

\section{El surgimiento de las disciplinas híbridas}

La necesidad de trascender la «objetividad fragmentada» a través de una explicación multidimensional o integrativa, ha motivado ya la aparición de nuevas propuestas epistemológicas y metodológicas. Dos aportes notables son si duda el principio de

\footnotetext{
1. La aparición de al menos 18 "disciplinas híbridas", fue el resultado de la integración de la ecologia (biológica) con otras tantas áreas del conocimiento. En efecto, desde su surgimiento y durante varias décadas, la ecología se vio confinada a la blología de la cual formó parte como una rama o sub-disciplina. Frente a la urgente necesidad de resolver una crisis ambiental de escala planetaria, numerosos investigadores de muy diferentes disciplinas se centraron en el análisis de todo un conjunto de problemáticas desde una perspectiva interdisciplinaria. A elio contribuyeron las acadérnicas interesadas en el universo natural. Ello provocó tanto la espacialización o topologización del estudio de la naturaleza, como su humanización o socialización. En el primer caso del estudio puntual y focalizado de los sistemes naturales, se pasó al de una escala regional y finalmente al de la dimensión planetaria. En el segundo, ganó consenso el principio de que la naturaleza
} no puede ser estudiada separada de la sociedad y de los seres humanos. 
complejidad de Edgar Morin $(1984 ; 1990)$ y lo que Rolando García (1993) ha denominado el estudio de los sistemas complejos. «Con el principio de complejidad se trata de superar el conocimiento en mundos separados propia de la 'ciencia clásica', [donde] ...ni las ciencias del hombre tienen conciencia del carácter físico y biológico de los fenómenos humanos, ni las ciencias de la naturaleza tienen conciencia de su inscripción en una cultura, una sociedad, una historia, ni de los principios ocultos que orientan sus elaboraciones» (Morin, 1984: 43). De esta forma una "ciencia con conciencia» como le denomina Morin será aquella que logre trascender (sin abolirlos) los distintos campos de las especialidades. Al fin y al cabo muchos de los problemas a resolver por los investigadores no se presentan en la realidad ya clasificados por disciplinas.

García (1993) por su parte, reconoce que ciertas situaciones donde confluyen múltiples procesos (por ejemplo del medio físico-biológico, de la producción, de la tecnología, demográfi$\cos$, de la organización social) constituyen la estructura de un sistema que funciona como una totalidad organizada, a la cual denomina sistema complejo y el cual solo es analizable desde un abordaje interdisciplinario. Ello obliga a plantear una estrategia de investigación que no puede quedar limitada a la simple «suma» de los enfoques parciales de los distintos especialistas, sino que debe constituir una verdadera interpretación sistémica que de lugar a un diagnóstico integrado.

Mas allá de los que han reflexionado estos y otros pensadores, en la práctica, la superación del parcelamiento cognitivo se ha ido dando no como un proceso autoconciente y generalizado, sino de una manera «espontánea», multipolar y asincrónica, es decir, ha surgido en diferentes momentos y en los diferentes campos o dominios del conocimiento ahí donde los problemas a resolver han inducido la creación de nuevos enfoques integradores.

El ejemplo mas ilustrativo de lo anterior lo constituyen los llamados «problemas ambientales», donde al paso del tiempo se ha ido descubriendo que estos pueden ser cabalmente descritos, interpretados y sobretodo resueltos, solamente a través de un enfoque integrativo. La problemática ambiental o ecológica constituye hoy en día lo que quizás es el reto mayor a la ciencia contemporánea, no solo porque demanda urgentemente nuevos enfoques capaces de ofrecer información confiable y completa para resolver numerosos problemas, sino especialmente porque estos representan ya una colosal amenaza a la supervivencia del planeta y de la sociedad humana.

Como respuesta a lo anterior se ha gestado un interesante fenómeno entre las diferentes campos de conocimiento que ha dado lugar a una serie de «disciplinas hibridas» las cuales operan como reacciones particulares al proceso general de parcelización y especialización excesiva y como expresiones de una suerte de «ciencia de salvamento» que busca ofrecer información para detener y remontar la crisis ambiental o ecológica. Este fenómeno presenta dos principales rasgos. En primer término ha tenido como principal «foco de infección» a la ecología, la disciplina que ha logrado una síntesis original de los conocimientos provenientes de las ciencias de la tierra y del mundo vivo, así como de la física y de la química, síntesis que cristalizó en la propuesta, rigurosidad y decantamiento del concepto de ecosistema, su objeto de estudio.

En segundo término, ha sido un proceso de carácter multipolar en el que por un lado se han ido paulatinamente venciendo las resistencias de los ecólogos empeñados en circunscribir su enfoque al mero estudio de los fenómenos de una naturaleza concebida como una entidad pura, pristina o intocada (Gómez-Pompa \& Kaus 1992; Ehrlich, 1997) y, por el otro, se han ido derribando las barreras de impermeabilidad y «pureza disciplinaria» en por lo menos 8 áreas del conocimiento. El resultado ha sido la aparición de casi una veintena de «disciplinas híbridas» (Figura 1), es decir, de formas interdisciplinarias de abordar la realidad, en las que el enfoque adoptado resulta de la integración del estudio sintético de la naturaleza (la ecología) con diferentes enfoques dedicados a estudiar el universo social o humano. Uno de estos nuevos campos lo conforma, sin duda, la «antropología ecológica» que hoy aborda diversos aspectos de ese fragmento de la realidad donde se encuentran la naturaleza y la cultura.

Figura $1^{*}$

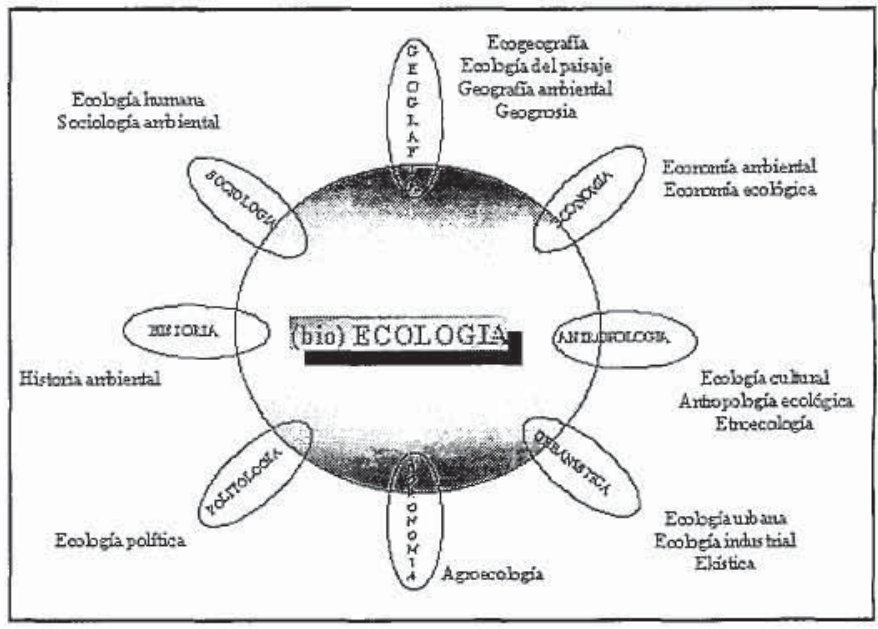

Visto desde una perspectiva sociológica, los factores detonadores de esta nuevas disciplinas híbridas, han sido sin duda, el proceso de globalización del fenómeno humano, el desarrollo mismo del conocimiento especializado, el despliegue de nuevas tecnologías y en el centro de todo ello, la aparición y el agudizamiento

\footnotetext{
La aparición de al menos 18 edisciplinas híbridas», fue el resultado de la integración de la ecologia (biológica) con otras tantas áreas del conocimiento. En efecto, desde su surgimiento y durante varias décadas, la ecología se vio confinada a la blología de la cual formó parte como una rama o sub-disciplina. Frente a la urgente necesidad de resolver una crisis ambiental de escala planeteri numerosos investigadores de muy diferentes disciplinas se centraron en ol análisis de pla as innovaciones tecnológicas que enlas uitimas decadas han permitido conocer con sumo detalle el espacio del planeta, y el surgimiento al interior de cada una de las ciencias sociales de corrientes académicas interesadas en el universo natural. Ello provocó tanto la espacialización o topologización del estudio de la naturaleza, como su humanización o socialización. En el primer caso, del estudio puntual y focalizado de los sistemas naturales, se pasó al de una escala regional $y$ finalmente al de la dimensión planetaria, En el segundo, ganó consenso el principlo de que la naturaleza no puede ser estudiada separada de la sociedad y de los seres humanos.
} 
de la llamada crisis ambiental o ecológica que, presente ya a una escala planetaria, se ha vuelto más frecuente, más grave y de mayor escala en las últimas décadas. Esta crisis ha obligado a replantear las formas convencionales de analizar las problemáticas y ha dado lugar a nuevos enfoques que, por lo común, giran alrededor de un paradigma central: el estudio integrado de la sociedad y de la naturaleza. Es entonces dentro de este contexto donde debe ubicarse el encuentro entre la antropología y la ecología, una relación que durante las últimas tres o cuatro décadas ha intentado dar lugar a un abordaje integrativo donde la cultura y la naturaleza aparecen como los dos universos centrales.

\section{La Antropología y la Ecología: Historia de un romance}

Hay ya una abundante literatura que da fe de un largo «romance» entre la antropología y la ecología. Véanse por orden de aparición las revisiones de Sahlins (1964), Netting (1971), Anderson (1974), Vayda \& McCay (1975), Hardesty (1977) y Orlove (1980). En la perspectiva latinoamericana debe citarse, además, la revisión crítica realizada por Vesuri (1994) bajo el término poco usual de «antropología ambiental». Los orígenes de esta convergencia están indisolublemente ligadas a las propuestas de J. Steward, quién fue el primer autor en proponer el uso explícito de conceptos ecológicos en la antropología en la década de los cincuenta. Aunque mucho se ha escrito sobre esta «ecología cultural» como le llamó Steward, los principales planteamientos de esta corriente pueden encontrarse en el libro de Netting (1977).

Vista en perspectiva, la antropología ecológica se ha beneficiado no solo de innumerables estudios empíricos sino de complejas reflexiones teóricas entre las que destacan el libro editado por E. Morán (1984) «The Concept of Ecosystem in Anthropology», la obra de Roy Ellen (1982) «Environment, Subsistence and System» y, más recientemente, el conjunto de ensayos reunidos en el libro de Descola \& Pálsson (1997), «Nature and Society: anthropological perspectives», donde se examinan los principales problemas téoricos de la interfase entre natutraleza y sociedad desde el ámbito particular de la antropología.

La multiplicación explosiva de estudios antropológicos donde los fenómenos culturales se abordan en franca correlación con los factores ecológicos hace muy difícil ofrecer un panorama coherente del devenir de esta corriente. Para complicar la situación, en los últimos años algunos antropólogos comienzan también a explorar las dimensiones espaciales de la cultura, expresados en la escala regional e incluso global (véanse las investigaciones pioneras de Collier, et al 1994 o Arizpe, 1997). No obstante lo anterior, es posible visualizar por lo menos cuatro ámbitos donde las aportaciones de los antropólogos han sido decisivas para entender las relaciones entre la sociedad y la naturaleza: (1) el estudio (desde un enfoque ecológico) de las ci- vilizaciones antiguas; (2) los estudios etnográficos que los «ecólogos culturales» han realizado sobre las sociedades premodernas contemporaneas (nómadas, tribales y campesinas); (3) el conjunto de investigaciones en torno a los sistemas de conocimiento y las percepciones no occidentales sobre la naturaleza (etno-ecología); y (4) las relaciones entre la diversidad cultural y la diversidad biológica y su conservación. En los cuatro casos, estas aportaciones han servido para reforzar una visión en donde la naturaleza no puede ser estudiada sin la sociedad, y lo social (incluyendo la cultura, la dinámica demográfica y la organización social) no puede ser explorado fuera de su contexto ecológico.

\section{El estudio de las civilizaciones antiguas desde una perspectiva ecológica y social}

En este primer caso se trata de los aportes de los arqueólogos y etno-historiadores de orientación ecológica que inspirados y/o influenciados por las obras de Leslie White y sobretodo de Julian Steward realizaron estudios para analizar las sociedades antiguas tomando en cuenta los factores ambientales. Aquí encontramos contribuciones donde la «evolución» de las civilizaciones estudiadas es el resultado de algun tipo de interacción entre esas sociedades y su entorno natural, una preocupación que tomó cuerpo de corriente teórica y metodológica en lo que Steward (1955) denominó justamente como «ecología cultural». Ello viene a explicar, de cierta forma, porqué un ensayo seminal de la antropología, el de K. Flannery (1972) sobre la evolución cultural de las civilizaciones, apareció publicado en una revista de ecología biológica.

Destacan aquí los análisis, verdaderos monumentos de la investigación, sobre Indonesia (C. Geertz), la región Amazónica (B. Meggers), los Andes (J.V. Murra), y sobretodo Mesoamérica, para solo citar los que son mas visibles. En el terreno de la teoría y de la metodología destaca asimismo la reflexión de Karl Butzer (1982) para quién la arqueología no es sino una suerte de ecología humana.

En el caso de la región mesoamericana son notables las aportaciones de los «ecólogos culturales» en el estudio tanto de las primeras sociedades de cazadores y recolectores como en el de las complejas civilizaciones de los períodos clásico y post-clásico (véanse las revisiones de Sanders \& Price, 1968; y McClung de Tapia, 1979). Aquí la lista de estudiosos incluye a autores tan celebres como M. Coe, K. Flannery, A. Palerm, E. Wolf, y W. Sanders, para solo citar a los más evidentes. La gran creatividad de estos estudios puede quedar ejemplificada por las espléndidas obras de McNeish (1967) y Flannery (1986) sobre los orígenes de la agricultura en el Valle de Tehuacan y en Oaxaca respectivamente, y la de Sanders y colaboradores (1979) sobre la historia de la cuenca del valle de México. No puede dejar de citarse, además, la escrupulosa investigación etnohistórica de T. Rojas-Rabiela (1988) sobre la agricultura de Mesoamérica en el siglo XVI. 


\section{Los estudios de las sociedades pre-moder- nas de la actualidad}

En el estudio de lo que bien puede llamarse una etnografía de corte ecológico deben distinguirse los análisis realizados en diferente sociedades pre-modernas del mundo contemporáneo: grupos nómadas (de cazadores-recolectores y pastoriles), sociedades tribales con algun tipo de horticultura, y comunidades campesinas de agricultores $\mathrm{y} / \mathrm{o}$ pescadores.

Se deben citar los nombres de por lo menos dos autores, cuyos estudios constituyen las investigaciones principales sobre la antropología ecólogica de las sociedades extractivistas o nómadas: R. B. Lee y T. Ingold. Es probable que el trabajo pionero de R. B. Lee entre los matorraleros del Kalahari constituya un parteaguas en los estudios antropológicos de los grupos nómadas (Lee \& De Vore, 1968), al aplicar conceptos de corte ecológico al estudio de esos grupos. Por su parte Ingold (1987) ha realizado un análisis profundo y detallado de las sociedades extractivas de cazadores y recolectores, mediante el decantamiento riguroso de la dimensión biológica y social de este estado del desarrollo humano.

Las sociedades tribales han sido recurrentemente abordadas por la antropología ecológica. Coronan esta corriente autores como Roy A. Rappaport, cuyo controvertido estudio sobre los Tsembaga de Nueva Guinea (1968) se volvió parteaguas de la etnología contemporanea, Roy R. Ellen, cuyo libro Environment, Subsistence and System (1972) es quizás el primer intento por generar una teoría de lo que ese autor denominó las sociedades de pequeña escalas (small-scale societies); y Philipe Descola -discípulo de LeviStrauss- quién ha realizado el que es quizás el análisis más profundo de las relaciones entre naturaleza y una sociedad tribal con su estudio sobre una comunidad indígena amazónica (Descola, 1988).

El estudio de las comunidades campesinas desde una perspectiva ecológica ha sido otro ámbito frecuentememte atendido por la antropología contemporánea. Se trata en este caso de unidades que, provenientes de antiguas civilizaciones, se hallan articuladas a sus respectivas sociedades nacionales a través de los mercados y los medios de comunicación y transporte. Aquí deben citarse los estudios descriptivos de S. Brush en los Andes y de G.A. Collier y L. Tyrtonia en México. El estudio de este último (Tyrtonia, 1992), ejemplifica en toda su dimensión lo que significa un estudio de comunidad rural desde la perspectiva de la ecología cultural. En otro sentido, los antropólogos se han aproximado a la comunidad rural o campesina participando de manera notable en la discusión, académica y política, sobre las formas de propiedad y el manejo de los recursos naturales. En este caso, sus aportaciones han contribuido a esclarecer la función de la propiedad comunitaria (los «commons») desde una perspectiva ecológica (véase Mc Cay \& Acheson, 1987).

Dentro de este ámbito, no puede dejar de señalarse la enorme importancia de la obra de Robert McC. Netting (1993), uno de los principales protagonistas de la ecología cultural, quién co- menzó estudiando comunidades rurales de Nigeria y Suiza y terminó privilegiando la unidad doméstica (household) o la familia de productores como unidad de análisis. En la tremenda discusión académica y política que hoy existe acerca de la supuesta superioridad de las grandes propiedades agroindustriales sobre la pequeña producción (véase Rosset, 1999 y Toledo, 2002), el libro de Netting (1993), «Smallholders, Householders: Farm families and the ecology of intensive, sustainable agriculture», hace una oportuna revalorización ecológica, tecnológica y cultural de la producción familiar a pequeña escala mediante una cuidadosa y detallada revisión del tema a nivel mundial. Su aportación es de cierta forma la culminación de una tradición ecológico-antropológica en la que autores como C. Meillasoux, A. Palerm. y E. Wolf jugaron un papel destacado, y cuyos aportes resultan esenciales en la visualización de un desarrollo rural alternativo.

\section{La Etnoecología: la apropiacion de la naturaleza}

Los seres humanos no solo realizan intercambios materiales con los ecosistemas, también Ilevan a cabo una apropiación intelectual del universo natural. Que las concepciones sobre la naturaleza varían social e históricamente, dado que son construcciones culturalmenmte determinadas, es un hecho casi obvio dentro de la antropología. Por ello, el desciframiento de las visiones y los conocimientos sobre la naturaleza y sus procesos han gestado el desarrollo de la etno-ecología, un campo donde los aportes de los antropólogos (etnólogos y linguistas) han sido determinantes. La tríada formada por H. C. Conklin, Ch. Frake y C. Levi-Strauss, inició, de hecho, el estudio contemporáneo del corpus pre-moderno o no-occidental. Conklin introdujo el término de etnoecología hace cinco décadas en su estudio clásico sobre los Hanunoo de las Filipinas (Conklin, 1954), en tanto que C. Levi-Strauss, dedicó un capítulo entero de su famoso libro "La Pensée Sauvage" (1964) al análisis del conocimiento no-occidental de la naturaleza.

Bstas aportaciones han sido cruciales en las discusiones que han tenido lugar en la última década sobre el cuestionamiento del monopolio ejercido por la ciencia, la cual se ha auto-constituido como el único conocimiento socialmente válido del mundo modemo. Por lo contrario, el reconocimiento de otras formas igualmente válidas y útiles de saber, ha otorgado una perspectiva renovadora y ha permitido desarrollar una crítica a la hegemonía de la ciencia. Fue justamente Claude Levi-Strauss quién de manera tajante estableció una distinción neta entre lo que denominó la "ciencia neolítica" y la "ciencia moderna" : "...para elaborar las técnicas, a menudo prolongadas y complejas, que perniten cultivar sin tierra, o bien sin agua, cambiar granos o raíces tóxicas en alimentos, o todavía más, utilizar esta toxicidad para la caza, el ritual o la guerra, no nos quepa la menor duda de que se requirió una actitud mental verdaderamente científica, una curiosidad asidua y perpetuamente despierta un gusto del conocimiento por el placer del conocer, pues una fracción solamente de las observaciones y de las experiencias podían dar resultados prácticos e inmediatamente utilizables"[1964:32]. 
Frente a la interrogante de porqué el conocimiento científico es tan reciente mientras que existieron grandes conquistas de la humanidad desde por lo menos hace diez mil años, situación a la que denominó la "paradoja neolítica", Levi-Strauss, responde "La paradoja no admite más que una solución: la de que existen dos modos distintos de pensamiento científico, que tanto el uno como el otro son función, no de etapas desiguales del desarrollo del espíritu humano, sino de los dos niveles estratégicos en que la naturaleza se deja atacar por el conocimiento científico: uno de ellos casi ajustado al de la percepción y el de la imaginación y el otro desplazado; como si las relaciones necesarias, que constituyen el objeto de toda ciencia, sea neolítica o moderna, pudiesen alcanzarse por dos vías diferentes: una de ellas muy cercana a la intuición sensible y la otra más alejada" [1964:33]. "...Esta ciencia de lo concreto tenía que estar, por esencia, limitada a otros resultados que los prometidos a las ciencias exactas naturales, pero no fue menos científica, y sus resultados no fueron menos reales. Obtenidos diez mil años antes que los otros, siguen siendo el sustrato de nuestra civilización" [1964:35].

Aunque la etnoecología es mas un enfoque («a way of looking»; véanse Fowler, 1977; Nazarea, 1999) que un campo bien demarcado del conocimiento o, si se prefiere, una multi-disciplina emergente en plena construcción (Toledo, 1992), las aportaciones surgidas en los últimos años la hacen aparecer como un nuevo campo de conocimiento híbrido porque cubre los tres dominios inseparables de todo sistema ecologico-social: la naturaleza, la producción y la cultura (véase Berkes, 1999; Toledo, 2002b). Por lo anterior, el estudio de cómo la naturaleza es visualizada, representada e interpretada localmente por una cierta cultura, a través de un conjunto de creencias y conocimientos, y cómo en términos de esas imágenes los miembros de esa cultura manejan y/o utilizan los recursos de la naturaleza, es lo que podemos llamar etnoecología (Toledo, 2002b). Ello se logra mediante el análisis integrado del complejo k-c-p, formado por el conjunto del kosmos (el sistema de creencias), el corpus (el repertorio de conocimientos) y la praxis (el conjunto de prácticas productivas) (Figura 2).

Figura $2^{*}$

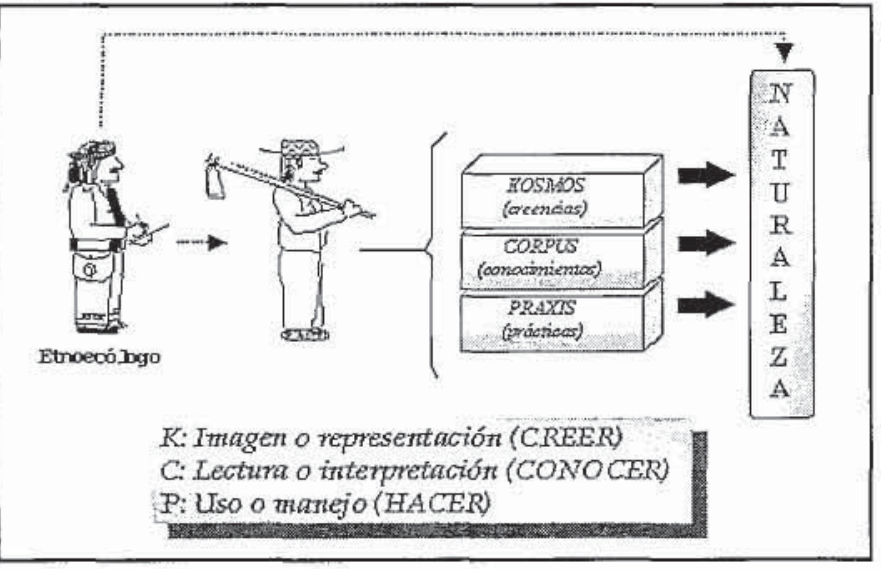

- La etnoecología es un nuevo enfoque de carécter multidisciplinario dedicado a estudiar de manera integrada el complejo formado por el conjunto de creencias (kosmos), conocimientos (corpus) y prácticas productivas (praxis), que una determinada cultura pone en juego durante la apropiaciôn de la naturaleza. Fuente: Toledo, 2002.
Dada la anterior perspectiva, se trata entonces de articular tres dominios de la investigación que nomalmente han sido abordados de manera separada. Mientras que la parte productiva (la apropiación material de la naturaleza) ha sido analizada fundamentalmente por agrónomos, ecólogos y geógrafos, el dominio del conocimiento (incluyendo las llamadas nomenclaturas y taxonomías tradicionales) ha sido coto de etnólogos y biólogos, en tanto que la parte de las cosmovisiones (mitos, ritos, percepciones) se convirtió en un dominio exclusivo de la antropología. En este último plano no pueden dejar de citarse los aportes transgresores (en tanto se preocuparon por ligar la porción "intangible" con la "material de las sociedades estudiadas) de dos antropólogos notables: G. ReichelDolmatoff y R.A. Rappaport, sin cuyos análisis estaríamos soslayando las "otras imágenes de la naturaleza», esto es, aquellas que construyen las culturas pre-modernas o indígenas .

Debemos a Reichel-Dolmatoff (1972) la primera interpretación coherente sobre el «intercambio simbólico» que se establece entre los miembros de las culturas tribales y sus ecosistemas, una interpretación que se conoce como el «modelo chamanístico». Reichel-Dolmatoff (op. cit.) logró revelar, a partir del estudio profundo de una cultura amazónica, las conexiones que se establecen entre los patrones de la producción (caza, pesca, recolección y horticultura), los elementos de la naturaleza concebidos como deidades, y las reglas de alimentación, salud e intercambio sexual; todo ello bajo la dirección y regulación de un actor fundamental: el chamán.

Por otra parte, las reflexiones teóricas que realiza R. Rappaport (1979) en su libro «Ecology, Meaning and Religion», han sido fundamentales en la revalorización de las formas pre-científicas de concebir a la naturaleza, mucho mas cercanas a una ética ecológica que las construcciones racionalistas que dominan en Occidente.

Varios antropólogos, además de agrónomos, geógrafos y ecólogos humanos, han contribuido directamente con estudios seminales que fundamentan la comprobación empírica de la llamada aproximación etnoecológica. Cuatro ejemplos notables son: el estudio de Rappaport (1968) sobre los Tsembaga de Nueva Guinea, el efectuado por Ellen (1978) acerca de los Nuaulu de Indonesia, el de Descola (1988) entre los Achuar en la Amazonia ecuatoriana y, en una perspectiva diferente, la revisión de escala mundial realizada por Barrera-Bassols \& Zinck (2000 y 2002) acerca del conocimiento de las culturas indígenas sobre los suelos (etno-pedología).

En todos estos casos, el ojo del analista se dedica a explorar las múltiples relaciones que se establecen entre las sociedades bajo estudio y su medio natural, en términos de sus concepciones, percepciones, conocimientos y formas de uso de los recursos locales. Otra es la dimensión aplicada, donde los estudios etnoecológicos están mostrando su enorme utilidad tanto en la búsqueda de nuevas maneras de utilizar los recursos naturales o ecosistemas (Berkes, et al, 2000; Toledo, et al. 2003), como en las políticas y estrategias de conservación biológica (Toledo, 2003a; 2003b), a partir de la revalorización rigurosa de las estrategias y formas de conocimiento y manejo de las culturas indígenas. 


\section{Antropología y Conservación: Biodiversi- dad y Diversidad Cultural}

Hay todavía un último campo, esta vez de investigación aplicada, donde comienza a ponerse en juego el enfoque interdisicplinario de la antropología ecológica. A diferencia de los anteriores se trata de un campo de reciente emergencia. Dado que en la última década se ha descubierto una estrecha correspondencia entre la diversidad biológica y la diversidad cultural del planeta (véase Harmon, 1995; Toledo, 2000; Maffi, 2001), la conservación de la biodiversidad, es decir, de la variedad de organismos biológicos que comparten con la especie humana el habitat planetario, se hace difícil e incluso imposible si no se reconocen, protegen y refuerzan las culturas indígenas ligadas con aquella.

En esta perspectiva se ha abierto un nuevo ámbito de colaboración entre la antropología y la ecología, que se expresa en la participación de antropólogos abordando aspectos tales como el papel de las comunidades indígenas en el mantenimiento y manejo de las áreas naturales protegidas o en el manejo y conservación in situ de la diversidad genética representada por las variedades domesticadas y cultivadas de plantas y animales (Orlove \& Brush, 1996). A lo anterior debe sumarse, por último, el reciente interés de linguistas y antropólogos por entender los mecanismos que han dado lugar a la diversidad linguística en estrecha relación con la diversidad biológica, y sobretodo, por establecer criterios para su estudio conjunto y su protección (véanse los ensayos reunidos en Maffi, 2001 y Stepp, et al., 2002), en lo que comienza a denominarse el axioma bio-cultural.

\section{Bibliografía}

ANDERSON, J. (1974) Ecological anthropology and anthropological ecology, En: Honigman, J. J. (Ed.) Handbook of Social and Cultural Antrhopology. Rand MCNally Press.

ARIZPE, L. (ed). (1997) Las Dimensiones Culturales del Cambio Global: una perspectiva antropológica. CRIM, Universidad Nacional Autónoma de México. 428 pp.

BARRERA-BASSOLS, N. \& J.A. ZINCK (2000) Ethnopedology in a worldwide perspective: an annotated Bibliography. ITC Punlication Vol. 77. Enschede, The Netherlands.

BARRERA-BASSOLS, N. \& J.A. ZINCK (2003) Ethnopedology: a worldwide view on the soil knowledge of local people. Geoderma 111: 171-195.

BERKES, F. (1999) Sacred Ecology: traditional ecological knowledge and resource management. Taylor \& Francis. 209 pp.
BERKES, F. \& C. FOLKE (eds) (1999) Linking Social and Ecological Systems. Cambridge University Press.

BERKES, F., J. COLDING \& C. FOLKE (2000) Rediscovery of traditional ecological knowledge as adaptive management. Ecological Applications 10: 1251-1262.

BUTZER, K.W. (1982) Archaeology as Human Ecology: method and theory for a contextual approach. Cambridge Univ. Press

COLLIER, G.A., D.C. MOUNTJOY \& R.B. NIGH. (1994) Peasant agriculture and global change. Bioscience 44:398-407

CONKLIN, H.C. (1954) An ethnoecological approach to shifting cultivation. Transactions of the New YorkAcademy of Sciences 17: $133-142$.

DESCOLA, PH. (1988) La Selva Culta: Simbolismo y Praxis en la Ecología de los Achuar. Ediciones Abya-Yala e Instituto Francés de Estudios Andinos. Quito, Ecuador.

DESCOLA, PH. \& G. PÁLSSON (eds)(1988) Nature and Society: anthropological perspectives. Routledge. 310 pp.

BLLEN, R.F. (1982) Environment, Subsistence and System: the ecology of small-scale societies. Cambridge Univ. Press.

FLANNERY, K. (1986) Guilá Naquitz. Academic Press. New York.

FLANNERY, K.(1972) The cultural evolution of civilizations. Annual Review of Ecology and Systematics 3:399-426

FOWLER, C. (1977) Ethnoecology. In: D. Hardesty (Ed). Ecological Anthropology. Wiley, New York.

FUNTOWICZ, S. \& J.R. RAVETZ (1993). Science for the postnormal age. Futures 25 (7): 35-38.

GARCÍA, R. 1994. Interdisciplinariedad y sistemas complejos. En: E. Leff (ed). Ciencias Sociales y Formación Ambiental. Gedisa, Editorial: 185-124.

GÓMEZ-POMPA, A. \&A. KAUS (1992) Taming the wilderness myth. Bioscience 42: 271-279.

GUDERSON, L.H. \& C.S. HOLLING (eds). (2001) Panarchy: understanding transformations in human and natural systems. Island Press.

HARDESTY, D.L. (1977) Ecological Anthropology. Wiley and Sons.

HARMON,D. (1996) Losing species, losing languages: connections between biological and linguistic diversity. Southwest Journal of Linguistics 15: 89-108 
INGOLD, T. (1987) The appropriation of nature. University of Iowa Press. Iowa. pp 287.

LEE, R.B. \& I. DE VORE (Eds). (1968) Man the Hunter. Chicago, Aldine.

LEFF, E. (ed). (2000) La Complejidad Ambiental. Siglo XXI Editores y Programa de Naciones para el Medio Ambiente. 314 pp.

MACNEISH, R. S. (1967) A summary of the subsistence. En: Byers, D.S. (Ed). The Prehistory of Tehuacam Valley. Vol. 1. Environment and Subsistence. University of Texas Press: 290-331

MAFFI, L. (ed).(2001) On Biocultural Diversity. Smithsonian Institution Press. Washington DC USA.

MCCAY, B. \& J.J. ACHESON (eds). (1987) The Question of the Commons: The Culture end Ecology of Communal Resources. The University of Arizona Press.

MCCLUNG DE TAPIA, E. (1979) Ecología y Cultura en Mesoamérica. Universidad Nacional Autónoma de México. 110 pp.

MEILLASSOUX, C. (1967) Recherche d'un niveau de déterminatione dans la societé cinegétique. L'Homme et la Sociéte 6:95-106.

MORAN, E. M. (Ed.) (1984) The Concept of Ecosystem in Anthropology. Westview Press.

MORIN, E. M . (1984) Ciencia con Conciencia. Anthropos. Madrid.

MORIN, E. M .(1990) Introducción al 1 Pensamiento Complejo.

MUMFORD, L. (1972) The Transformation of Man. Harper \& Row, New York.

NAREDO, J.M. (1992) El oscurantismo territorial de las especialidades científicas. En: Gonzalez, A.J. y M. Gonzalez de Molina (Eds.) La Tierra. Mitos, Ritos y Realidades. Editorial Anthropos: 109-144.

NAZAREA, V. (Ed). (1999) Ethnoecology: situated knowledge/ located lives. The University of Arizona Press. 299 pp.

NETTING, R. MCC. (1971) The ecological approach in cultural study. McCaleb Module in Anthropology. Addison-Wesley Publishing Co. Reading $30 \mathrm{pp}$.

NETTING, R. MCC. (1977) Cultural Ecology. Cummings, Menlo Park.

NETTING, R. MCC. (1993) Smallholders, Householders: farm families and the ecology of intensive, sustainable agriculture. Stanford Univ. Press.
ORLOVE, B. (1980) Ecological anthropology. Annu. Rev. Anthropol. 9:235-273.

ORLOVE, B. \& S.B. BRUSH. (1996) Anthropology and the conservation of biodiversity. Annu. Rev. Anthropol. 25: 329-352

RAPPAPORT, R.A. (1968) Pigs for the Ancestors: ritual in the ecology of a New Guinea people. Yale University Press.

RAPPAPORT, R.A. (1979) Ecology, Meaning and Religion. North Atlantic Books.

REICHEL-DOLMATOFF, G. (1976) Cosmology as ecological analysis: a view from the rain forest. Man 11:307-318

ROJAS-RABIELA, T. (1988) Las Siembras de Ayer: la agricultura indígena del siglo XVI. CIESAS/ Secretaría de Educación Pública. México.

ROSSET, P. (1999) On the benefits of Small Farms. Food First Backgrounder 6(4): 1-4.

SANDERS, W.T. \& B.J. PRICE. (1968) Mesoamerica: the evolution of a civilization. Random House, New York.

SANDERS, W.T., J. PARSONS \& R.S. STANLEY. (1979) The Basin of Mexico:ecological processes in the evolution of a civilization. Academic Press.

SAHLINS, M.D. (1964) Culture and environment: the study of cultural ecology. En: Tax, S. (Ed) Horizons of Anthropology. Aldine Publish.

SCHMIDT, A. (1976) El Concepto de Naturaleza en Marx. Siglo XXI. pp 244.

STEPP J.R. (eds). (2001) Ethnobiology and Biocultural Diversity. International Society of Ethnobiology, Georgia, USA.

STEWARD, J. (1955) Theory of Culture Change. University of Mlinois Press.

TOLEDO, V.M. (1992) Ethnoecology: origins, scope and implications of a rising discipline. Etnoecológica 1:5-13.

TOLEDO, V.M.. (2001) Indigenous peoples and biodiversity. En: S. Levin, et al (Eds). Encyclopedia of Biodiversity. Academic Press: 1181-1197

TOLEDO, V.M. (2002a) Agroecología, sustentabilidad y reforma agraria: la superioridad de la pequeña producción. Agroecologia e Desenvolvimento Rural Sustentavel (Brasil) 3(2): 27-36.

TOLEDO, V.M. (2002b) Ethnoecology: a conceptual framework for the study of indigenous knowledge of nature. In: J.R. Stepp et al (eds), Ethnobiology and Biocultural Diversity. International Society of Ethnobiology, Georgia, USA: 511-522. 
TOLEDO, V.M..(2003) Los pueblos indígenas: actores estratégicos para el Corredor Biológico Mesoamericano. Biodiversitas 47: $8-15$

TOLEDO, V. M., P. ALARCÓN-CHÁIRES, P. MOGUEL, M. OLIVO, A, CABRERA, E. LEYEQUIEN \& A. RODRÍGUEZALDABE. (2001) El Atlas Etnoecológico de México y Centroamérica. Etnoecológica 8: 6-17.

TOLEDO, V.M, B. ORTIZ-ESPEJEL, L: CORTÉS, P. MOGUEL \& M.J. ORDÓÑEZ. (2003) The múltiple use of tropical forests by indigenous peoples in México: a case of adaptive management. Conservation Ecology (en prensa).

TYRTONIA, L.(1992) Yagavila: un ensayo en ecología cultural. Universidad Autónoma Metropolitana. México DF.

VAYDA, A.P. \& B.J. MCCAY (1975) New directions in ecology and ecological anthropology. Annual Review of Anthropology 4:293-306.

VESSURI, H. (1994) La formación en antropología ambiental a nivel universitario. En: E. Leff (ed), Ciencias Sociales y Formación Ambiental. GEDISA Editorial: 181-222 